\title{
TROPHININ AND INTEGRIN $\beta_{3}$ EXPRESSION IN THE HUMAN ENDOMETRIUM. A PILOT STUDY
}

\author{
Piret Männik ${ }^{l}$, Ragnar Toomas Kibur ${ }^{l}$, Andres Arend ${ }^{1}$, \\ Marina Aunapuu, ${ }^{1,2}$ \\ ${ }^{1}$ Department of Anatomy, University of Tartu, Estonia \\ ${ }^{2}$ Department of Morphology, Estonian University of Life Sciences, Tartu, Estonia
}

\begin{abstract}
The study involved ten patients with tubal factor infertility. Patients (Group I, age 28-34 years, n=5; Group II, age $35-40$ years, $n=5$ ) underwent endometrial biopsy on postovulatory days $7-10$ of the natural menstrual cycle. Endometrial biopsies were studied by histological methods, presence of trophinin and integrin $\beta_{3}$ in the endometrial surface epithelium and in the glandular epithelium was assessed by immunohistochemistry.

Low levels of $\beta_{3}$ integrin and trophinin were estimated in the endometrial epithelial cells in most patients, particularly in Group II, which reflects reduced endometrial capacity for adhesion and points to problems with the implantation of the embryo.
\end{abstract}

Key words: endometrium, infertility, immunohistochemistry, trophinin, integrin $\beta_{3}$.

\section{INTRODUCTION}

Infertility is a condition that affects a couple and is defined as the lack of conception after an arbitrary period of 12 months with regular sexual intercourse and without using any contraception. Female infertility is mainly caused by tubal factor infertility, impaired endometrial function and endocrine dysfunctions [3]. During the last decades, more attention has been paid to different immunohistochemical studies of the endometrium, which should contribute to figuring out the specific roles and locations of epithelial cell proteins, essential for implantation. 
Trophinin is one of the membrane proteins involved in the implantation process. Trophinin mediates apical cell adhesion and is expressed during formation of the placenta in trophoblast and at the implantation site on the endometrial luminal epithelium at the time of embryo implantation. Trophinin and trophinin-associated cytoplasmic proteins tastin and bystin are expressed on the human placenta during the early stages of pregnancy and can only be found in the placenta at the beginning of the first trimester. The role of trophinin in the implantation process diverges significantly among species. Trophinin probably does not have a crucial role in embryo implantation and placental development in the mouse because trophinin gene knock-out mice are still fertile [11].

Trophinin, tastin, and bystin form a unique complex mediating apical cell adhesion between human trophoblasts and endometrial epithelial cells. Trophinin proteins have been found in the cytoplasm of syncytiotrophoblast of chorionic villi and in decidualized endometrial stroma [12]. Trophinin mediates adhesion of syncytiotrophoblastic cells to the apical plasma membranes. Trophinin is not a typical membrane protein. The N-terminal region contains about $70 \times 10^{6}$ amino acid residues, is hydrophilic and is predicted to be localized in the cytoplasm. Resulting from that, this region is identifiable for the region-specific antibodies only if the cells are permeabilized. The rest of the trophinin molecule, including the C-terminal region, consists of decapeptide repetitions from which three are relatively hydrophobic and three relatively hydrophilic, indicating a true membrane protein. The three relatively hydrophilic regions are predicted to be expressed on the cell surface.

Implantation of the trophoblast during normal pregnancy is a strictly regulated and controlled process. However, the processes of trophoblastic invasion are similar to those of malignant tumour metastasis, as both processes are often accompanied by aggressive cell proliferation, host cell destruction, and angiogenesis $[13,16]$.

Trophinin is a molecule associated with implantation of the human embryo. Finding out its specific roles could contribute to a better understanding of placentar processes. Human endometrium tightly regulates expression of trophinin, which is expressed only within a restricted region of the apical side of luminal endometrial epithelium at a time coincident with the "window of implantation" (WOI). During early stages of pregnancy trophinin, tastin and bystin are strongly 
expressed in the human placenta, especially in the trophoblast of chorionic villi and in the endometrial glandular epithelium, particularly at the utero-placental interface. In ectopic pregnancies (intrinsic for humans), trophinin is expressed in the trophoblast as well as in the epithelium of the fallopian tube. Studies suggest that trophinin plays an important role in human embryo implantation, including the pathogenesis of ectopic pregnancy [12].

Integrins form a class of cell surface proteins, which mediate cellcell and cell-extracellular matrix attachment $[4,15]$. Integrins, heterodimeric transmembrane extracellular matrix receptors, are important in implantation of an embryo in the stage of adhesion. Integrins function as receptors between molecules of extracellular matrix and adhesion molecules of cells [15]. Nine different $\alpha$ and $\beta$ subunits are known to exist in human endometrium. By combining with one another, they may carry out different functions in the epithelium [5]. During the WOI, presence of integrins $\alpha_{1} \beta_{1}, \alpha 4 \beta_{1}$ ja $\alpha v \beta_{3}$ has been found in the human Fallopian tube epithelium [17]. Studies have shown that integrin $\beta_{3}$ exists in both the Fallopian tube epithelium and endometrial epithelium; it is up-regulated during receptivity period of the endometrium. Disturbances in the expression of integrin $\beta_{3}$ have been found in the case of female infertility and disorders of the luteal phase $[6,7]$.

In this study we focused on immunohistochemical analysis of trophinin and integrin $\beta_{3}$ protein expression in the endometrium of TFI patients.

\section{MATERIAL AND METHODS}

Endometrial biopsies of ten patients in reproductive age were collected in Nova Vita Clinic (Tallinn, Estonia). The biopsy was taken under general anaesthesia between the $7^{\text {th }}$ and $10^{\text {th }}$ post-ovulation day in the natural menstrual cycle which corresponded to the endometrium implantation phase, i.e. the $21^{\text {st }}$ to $24^{\text {th }}$ cycle day. The age of Goup I patients was under 34 years $(n=5$; mean age $30.0 \pm 0.7)$; the age of Group II patients was higher that 34 years $(n=5$; mean age $37.2 \pm 1.0)$. Endometrial biopsies were obtained from informed women in a protocol approved by the Ethics Review Committee on Human Research of the University of Tartu. 
Patients were numbered consequently according to their enrollment into the study.

Serum progesterone levels were normal in all patients except one patient (no 1) of Group II with very low levels.

\section{Histology}

The specimens for light microscopy were fixed in $10 \%$ buffered formalin and embedded in paraffin with a vacuum processor Tissue$\mathrm{Tek}^{\circledR} \mathrm{VIP}^{\mathrm{TM}} 5 \mathrm{Jr}$ (Sakura, USA). Specimens were cut with microtome Ergostar HM 200 (Microm, Germany) at three- $\mu \mathrm{m}$ thickness and stained using hematoxylin-eosin and van Gieson methods for general orientation to sections. Slides were observed and photographed by a Zeiss Axiophot-2 microscope (Zeiss, Germany).

\section{Immunohistochemistry}

$3 \mu \mathrm{m}$ thick paraffin sections mounted on poly-L-lysine coated SuperFrost slides (Menzel-Gläser, Germany) were deparaffinized and rehydrated. Peroxidase activity was removed by $0.6 \% \mathrm{H}_{2} \mathrm{O}_{2}$ (Merck, Germany) in methanol (Merck, Germany). Then sections were washed in tap water and in PBS ( $\mathrm{pH}=7.4$; Gibco, Invitrogen, USA) for $10 \mathrm{~min}$, treated with normal $1.5 \%$ goat serum (Gibco, Invitrogen Corporation, USA) for $30 \mathrm{~min}$ at room temperature and incubated with the first antibody [trophinin (Abcam, UK) diluted 1:500; integrin $\beta_{3}$ (CD61, Dako) diluted 1:250] overnight at $4^{\circ} \mathrm{C}$ in the humidity chamber. In the next day, sections were washed in PBS and incubated with the universal secondary antibody (VECTASTAIN ABC Universal Kit, Burlingame, USA) for $30 \mathrm{~min}$ at room temperature. Sections were washed with PBS and peroxidatic activity was detected with DAB (Vector, USA) applied for $5 \mathrm{~min}$ at room temperature. Then sections were rinsed, counterstained with haematoxylin, dehydrated and mounted with DPX (Fluka, Switzerland). Trophinin and integrin $\beta_{3}$ labeling was expressed by a subjective scale ranging from 0 to $4(0-$ no reaction; 1 - minimal reaction; 2 - weak reaction; 3 - moderate reaction; 4 - strong reaction). Two independent observers in a blinded fashion performed the evaluation. Immunohistochemical negative controls were performed by omitting primary antibody. 
Trophinin and integrin $\beta_{3}$ expression in the human endometrium ... 307

\section{Statistics}

To compare results of immunohistochemical studies of group I and II, Mann-Whitney U-test was applied.

\section{RESULTS}

\section{Histology}

The histological studies showed the normal structure of the endometrial columnar epithelium in eight patients' biopsy. In two patients' biopsies (Group II) the endometrial columnar epithelium was changed - the cells were low with irregular shape. Connective tissue stroma in all patients' biopsies was, as a rule, rich in cells.

\section{Immunohistochemistry}

Immunohistochemical staining with trophinin showed a weak reaction (grade 2) in two patients' luminal epithelium (Figure 1) and a minimal reaction (grade 1) in four patients' luminal epithelium and two patients' glandular epithelium (Table 1). In Group II (patients older than 34 years), trophinin level was lower than in Group I patients, but the difference was not statistically significant. In Group I (patients younger than 34 years), integrin $\beta_{3}$ expression in the epithelium of uterine glands was high in one patient (no 7, Table 1, Figure 2). In other patients results varied from minimal to moderate reaction (Table 1), but in Group II (patients older than 34 years) integrin level was significantly lower compared to younger patients (Group I). 


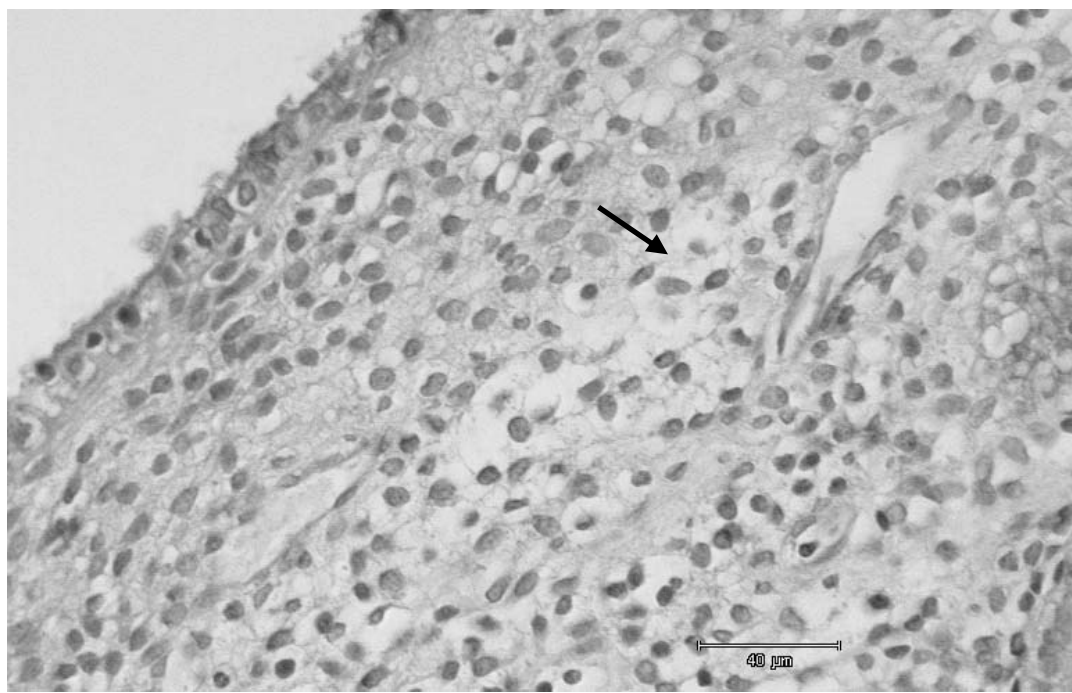

Figure 1. Minimal positive reaction to trophinin in the endometrial luminal epithelium (arrow). DAB + haematoxylin.

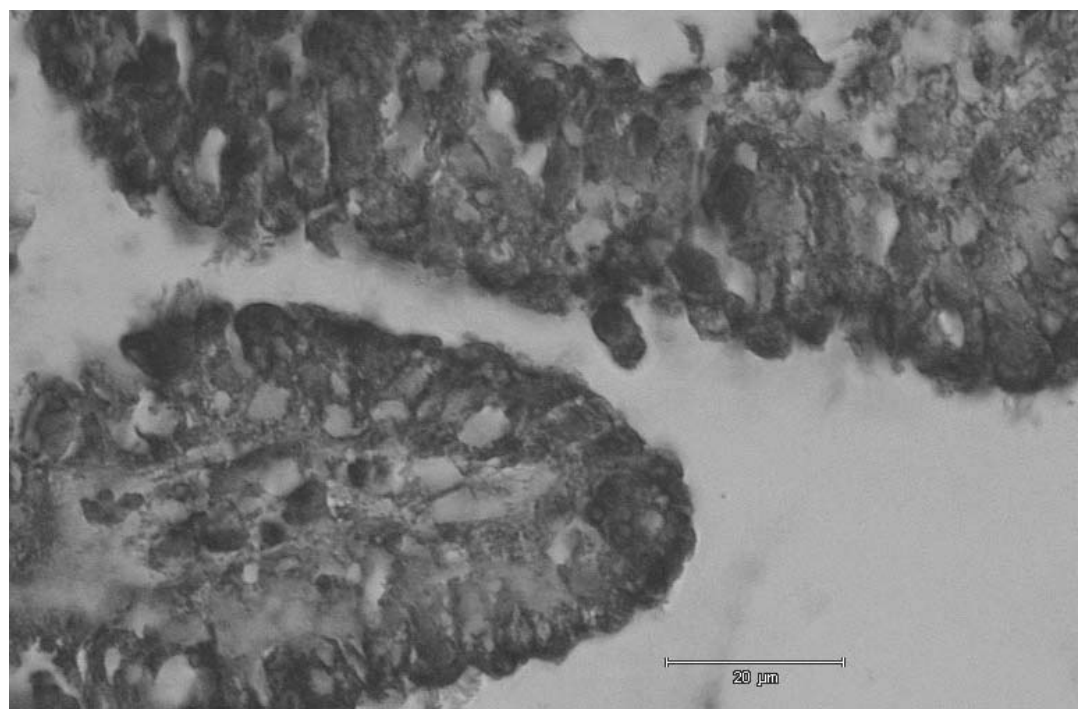

Figure 2. Strong integrin $\beta_{3}$ immunohistochemical reaction in the endometrial glandular epithelium. DAB+hemalaun. 
Trophinin and integrin $\beta_{3}$ expression in the human endometrium ... 309

Table 1. Results of immunohistochemical study

\begin{tabular}{|l|c|c|c|c|}
\hline Group I & \multicolumn{2}{|c|}{ Integrin $\beta_{3}$} & \multicolumn{2}{c|}{ Trophinin } \\
\hline & EL & EG & EL & EG \\
\hline 2 & 1 & 2 & 2 & 1 \\
\hline 4 & 2 & 1 & 0 & 0 \\
\hline 5 & 1 & 1 & 1 & 0 \\
\hline 6 & 2 & 3 & 0 & 0 \\
\hline 7 & 2 & 4 & 2 & 1 \\
\hline $\mathrm{X} \pm$ SEM & $\mathbf{1 , 6} \pm \mathbf{0 , 3}$ & $\mathbf{2 , 2} \pm \mathbf{0 , 6}$ & $\mathbf{1} \pm \mathbf{0 , 5}$ & $\mathbf{0 , 4} \pm \mathbf{0 , 3}$ \\
\hline Group II & & & & \\
\hline 1 & 0 & 1 & 1 & 0 \\
\hline 3 & 1 & 0 & 0 & 0 \\
\hline 8 & 1 & 1 & 0 & 0 \\
\hline 9 & 0 & 0 & 1 & 0 \\
\hline 10 & 0 & 0 & 1 & 0 \\
\hline $\mathrm{X} \pm$ SEM & $\mathbf{0 , 4} \pm \mathbf{0 3} *$ & $\mathbf{0 , 4} \pm \mathbf{0 , 3}$ * & $\mathbf{0 , 6} \pm \mathbf{0 , 3}$ & $\mathbf{0}$ \\
\hline
\end{tabular}

EL - luminal epithelium; EG - glandular epithelium;

0 - no reaction; 1 - minimal reaction; 2 - weak reaction; 3 - moderate reaction; 4 strong reaction

$* \mathrm{P}<0.005$ Group I vs Group II

\section{DISCUSSION}

Endometrial maturation is a complex physiological process where tissue remodelling results in permissive environment for embryo invasion. Endometrium goes through proliferative, secretory and menstrual phases during spontaneous menstrual cycle, and histological changes of endometrium are strongly regulated by ovarian steroid hormones. According to literature, approximately 70 million couples suffer from infertility over the world, and only half of them are seeking infertility medical care [1]. In female infertility the main reasons are changes in the functional reproductive organs [5, 18], which can originate from hormonal problems as well as from different reproductive organ pathologies (e.g. ovarian pathologies, endometriosis, uterine pathology). Successful implantation of the blastocyst requires a receptive endometrium. The process is completed during the second embryonic week [5]. During the last decades, more attention has been paid to various immunohistochemical studies [10], which should contribute to finding out the 
specific roles and locations of different epithelial cell proteins essential for implantation. During the initial phase of implantation, fetal trophoblast cells invade and migrate into the maternal decidua [19], during which molecular bonds form between trophoblast and the epithelial cells via L-selectine. Also a molecular complex of trophinin, tastin, and bystin comprising a complex mediating cell adhesion between trophoblast and endometrial epithelial cells is considered important [16]. Trophinin is a complex membranous protein a part of which is expressed on the cell surface. In complex with trophinin, cytoplasmatic proteins tastin and bystin regulate the activity of trophinin (which in turn regulates activity of cellular adhesion). In our immunohistochemical study, the assessed level of trophinin in the patients' biopsies of luminal epithelium was low or absent, in particular in Group II with patients aged over 35 years (Table 1), which could serve as a potential factor promoting infertility. Identified low levels of trophinin or the lack of the protein on the patient's luminal and glandular epithelium acknowledges limited capability for adhesion resulting in impaired implantation.

At blastocyst implantation, an important role is played by integrins which function as receptors between molecules of extracellular matrix and adhesion molecules [15]. Luminal epithelial cells express several integrins, but during WOI increased expression of $\alpha v \beta_{3}$ integrin has been reported [8]. In addition to endometrial cells, expression of integrins is noted in embryo trophoblast [21]. It has also been shown that the expression of endometrial $\alpha v \beta_{3}$ integrin correlates with the pregnancy outcome of IVF [5]. On the other hand, in a study where expression of integrins in the endometrium was compared between fertile women of the control group with women who had undergone IVF procedures, no differences were found in the integrin expression between these two groups [20]. At the same time, when $\beta_{3}$ integrin endometrial expression was compared between fertile and infertile women, a lower level of integrin expression was found in the endometrial glandular epithelium of infertile women but not in the surface epithelium [2]. In our study strong $\beta_{3}$ integrin staining in the glandular epithelium was seen in one patient only (no 7), and moderate staining in another patient (no 6) of Group I, while in surface epithelium only minimal or weak staining was found (Table 1). In Group II (patients aged over 35 years), $\beta_{3}$ integrin staining was weak or missed entirely (Table 1), which once more reflects problems with implantation 
of an embryo in these patients, particularly in patients of advancing age. The age of patients has been found to play an important role in the outcome of IVF procedures. For example in a Singapore study, fertilization rates of 151 patients who underwent IVF procedures were $50.9 \%$ in 34 -year-old or younger women, $49.3 \%$ in the group of women aged 35-39 years, and $37.9 \%$ in women aged 40 years or older. The pregnancy rates were $43.2 \%, 32.7 \%$, and $14.3 \%$, respectively [9]. Similar age-dependent results have also been obtained in another investigation where pregnancy rates of patients undergoing assisted reproduction declined from $48.8 \%$ in women aged less than 30 years to $13.6 \%$ in women aged over 42 years [14] and in a retrospective study based on 230 patients where the effect of age on success in women undergoing in vitro fertilization was assessed. Patients were divided into two groups with age either under or over 35 years and the study demonstrated a decline in pregnancy rate from $35.17 \%$ in women younger than 35 years to $17.93 \%$ in women older than 35 years. It has been found that the impaired implantation efficiency seen in older women is apparently independent of the magnitude of their stimulation response. "Oocyte factors" are felt to be primarily responsible; however, some available data suggest that uterine factors, e.g. diminished endometrial receptivity, may also play a role [14].

Formation of endometrium is a complex physiological process in which receptivity for embryonic implantation is established. Although individual morphological and molecular markers involved in the implantation process are well known and thoroughly studied, a complex overview of the significance of different markers and the dynamics of the process on the whole is still lacking. We think that the studies of the endometrium need an integral approach to the subject, involving different morphological methods e.g. histology, immunohistochemistry, gene- and ultrastructure studies, forming a whole picture of the processes in question.

\section{ACKNOWLEDGEMENTS}

The study was supported by Estonian Science Grant No. 7301. The authors are grateful to Prof. A. Salumets for his help in collecting of the samples. 


\section{REFERENCES}

1. Boivin J., Bunting L., Collins J.A., Nygren K.G. (2007) International estimates of infertility prevalence and treatment-seeking: potential need and demand for infertility medical care. Hum Reprod, 22, 6, 15061512.

2. Boroujerdnia MG, Nikbakht R. (2008) Beta3 integrin expression within uterine endometrium and its relationship with unexplained infertility. Pak J Biol Sci, 11(21):2495-9.

3. Coutifaris C., Myers E.R., Guzick D.S., Diamond M.P., Carson S.A., Legro R.S., McGovern P.G., Schlaff W.D., Carr B.R., Steinkampf M.P., Silva S., Vogel D.L., Leppert P.C. (2004) Histological dating of timed endometrial biopsy tissue is not related to fertility status. Fertil Steril, 82, 5, 1264-1272.

4. Grosskinsky C.M., Yowell C.W., Sun J., Parise L.V., Lessey B.A. (1996) Modulation of integrin expression in endometrial stromal cells in vitro. J Clin Endocrinol Metab, 81, 2047-2054.

5. Guzeloglu-Kayisli O., Basar M., Arici A. (2007) Basic aspects of implantation. Reprod Biomed Online, 15, 728-739.

6. Lessey B.A., Damjanovich L., Coutifaris C., Castelbaum A., Albelda S.M., Buck C.A. (1992) Integrin adhesion molecules in the human endometrium. Correlation with the normal and abnormal menstrual cycle. Clin Invest, 90, 188-195.

7. Lessey B.A., Castelbaum A.J. (1995) Integrins in the endometrium of women with endometriosis. Br J Obstet Gynaecol, 102, 347-348.

8. Lessey, B.A.; Damjanovich, L.; Coutifaris, C.; Castelbaum, A.; Albelda, S.M.; Buck C.A. (1992) Integrin adhesion molecules in the human endometrium. Correlation with the normal and abnormal menstrual cycle. Clin Invest, 90, 188-195.

9. Lim A.S., Tsakok M.F. (1997) Age-related decline in fertility: a link to degenerative oocyte? Fertil Steril, 68(2), 265-71.

10. Meyer W.R., Castelbaum A.J., Somkuti S., Sagoskin A.W., Doyle M., Harris J.E., Lessey B.A. (1997) Hydrosalpinges adversely affect markers of endometrial receptivity. Hum Reprod, 12, 1393-8.

11. Nadano D., Sugihara K., Paria B.C., Saburi S., Copeland N.G., Gilbert D.J., Jenkins N.A., Nakayama J., Fukuda M.N. (2002) Significant differences between mouse and human trophinins are revealed by their expression patterns and targeted disruption of mouse trophinin gene. Biol Reprod, 66, 313-21.

12. Nakayama J., Aoki D., Suga T., Akama T.O., Ishizone S., Yamaguchi H., Imakawa K., Nadano D., Fazleabas A.T., Katsuyama T., 
Nozawa S., Fukuda M.N. (2003) Implantation-Dependent Expression of Trophinin by Maternal Fallopian Tube Epithelia during Tubal Pregnancies. Am J Pathol, 163, 2211-2219.

13. Nikas G. (1999) Cell-surface morphological events relevant to human implantation. Hum Reprod, 14, 37-44.

14. Rosenwaks Z., Davis O.K., Damario M.A. (1995) The role of maternal age in assisted reproduction. Hum Reprod, 10, Suppl 1, 165-73.

15. Ruoslahti E. (1991) Integrins. J. Clin Invest, 87, 1-5.

16. Suzuki N., Nakayama J., Shih I.M., Aoki D., Nozawa S., Fukuda M.N. (1999) Expression of Trophinin, Tastin, and Bystin by Trophoblast and Endometrial Cells in Human Placenta. Biol Reprod, 60, 621-627.

17. Sülz L., Valenzuela J.P., Salvatierra A.M., Ortiz M.E., Croxatto H.B. (19989 The expression of $\alpha \mathrm{v}$ and $\beta 3$ integrin subunits in the normal human Fallopian tube epithelium suggests the occurence of a tubal implantation window. Hum. Reprod, 13, 2916-2920.

18. Thie M., Röspel R., Dettmann W., Benoit M., Ludwig M., Gaub H., Denker H.W. (1998) Interactions between trophoblast and uterine epithelium: monitoring of adhesive forces. Hum Reprod, 13, 32113219.

19. Tanya D. Burrows., King A., Y.W. Loke Y.W. (1996) Trophoblast migration during human placental implantation. Hum Reprod Update, 4, 307-321.

20. Thomas, K.; Thomson, A.; Wood, S.; Kingsland, C.; Vince, G.; LewinJones, I. (2003) Endometrial integrin expression in women undergoing in vitro fertilization and the association with subsequent treatment outcome. Fertil. Steril, 80, 502-507.

21. Wang, J.; Armant, D.R. (2002) Integrin-mediated adhesion and signaling during blastocyst implantation. Cells Tissues Organs, 172, 190-201.

\section{Address for correspondence:}

Marina Aunapuu

University of Tartu

Department of Anatomy

Ravila 19, Biomedicum, 50411 Tartu, Estonia

E-mail: marina.aunapuu@ut.ee 